\title{
Assay of steroids by liquid chromatography- tandem mass spectrometry in monitoring 21-hydroxylase deficiency
}

\author{
Sandra R Dahl1, *, Ingrid Nermoen ${ }^{2,3, *}$, Ingeborg Brønstad ${ }^{4,5}$, Eystein S Husebye ${ }^{6,7,8}, K_{\text {ristian Løvås }}^{6,7,8}$ and \\ Per M Thorsby ${ }^{1}$
}

${ }^{1}$ Hormone Laboratory, Department of Medical Biochemistry, Oslo University Hospital, Oslo, Norway

${ }^{2}$ Institute of Clinical Medicine, University of Oslo, Oslo, Norway

${ }^{3}$ Division of Medicine, Akershus University Hospital, Lørenskog, Norway

${ }^{4}$ National Centre for Ultrasound in Gastroenterology, Haukeland University Hospital, Bergen, Norway

${ }^{5}$ Department of Clinical Medicine, University of Bergen, Bergen, Norway

${ }^{6}$ Department of Clinical Science, University of Bergen, Bergen, Norway

${ }^{7}$ K.G. Jebsen-Center for Autoimmune Diseases, University of Bergen, Bergen, Norway

${ }^{8}$ Department of Medicine, Haukeland University Hospital, Bergen, Norway

Correspondence should be addressed to I Nermoen: ingrid.nermoen@ahus.no

*(S R Dahl and I Nermoen contributed equally to this work)

\begin{abstract}
Immunoassays of steroid hormones are still used in the diagnosis and monitoring of patients with congenital adrenal hyperplasia. However, cross-reactivity between steroids can give rise to falsely elevated steroid levels. Here, we compare the use of immunoassays and liquid chromatography-tandem mass spectrometry (LC-MS/MS) in the monitoring of patients with classic 21-hydroxylase deficiency (21OHD). Steroid profiles in different mutation groups (genotypes) were also compared. Fifty-five patients with classic 210HD (38 women) were studied. Blood samples were collected in the morning after an overnight medication fast. LC-MS/MS and immunoassays were employed to assay 17-hydroxyprogesterone (17OHP), testosterone and androstenedione. In addition, 21-deoxycortisol (21DF), 11-deoxycortisol (11DF), corticosterone, deoxycorticosterone, cortisone and cortisol were analyzed by LC-MS/MS. Testosterone, androstenedione and 170HP levels were consistently lower (by about 30-50\%) when measured by LC-MS/ MS compared with immunoassays, with exception of testosterone in men. There was a significant correlation between 21DF and 170HP $(r=0.87, P<0.001)$, but three patients had undetectable 21DF. Subjects with no enzyme activity had significantly lower mean 11DF concentrations than subjects with residual activity. The use of LC-MS/MS gives a more specific view of adrenal steroid levels in $210 \mathrm{HD}$ compared with immunoassays, which seem to considerably overestimate the levels of $17 \mathrm{OHP}$ and androstenedione. Falsely elevated levels of $17 \mathrm{OHP}$ and androstenedione could lead to overtreatment with glucocorticoids.
\end{abstract}

Key Words
- 21 -hydroxylase deficiency
- congenital adrenal
hyperplasia
- LC-MS/MS
- monitoring
- adrenal glucocorticoid
quantitation
- adrenal androgens
quantitation

Endocrine Connections (2018) 7, 1542-1550

\section{Introduction}

Congenital adrenal hyperplasia (CAH) is a group of autosomal recessive disorders with impaired biosynthesis of adrenal glucocorticosteroids and defects in cortisol biosynthesis. More than 95\% of cases are caused by mutations in CYP21A2 encoding 21-hydroxylase, a key enzyme in the aldosterone and cortisol pathway $(1,2)$. The classic form of 21-hydroxylase deficiency (21OHD) includes the salt-wasting (SW) form with complete lack https://ec.bioscientifica.com https://doi.org/10.1530/EC-18-0453
() 2018 The authors Published by Bioscientifica Ltd

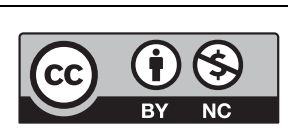

This work is licensed under a Creative Commons Attribution-NonCommercial 4.0 International License. 
of cortisol and aldosterone production, and the simple virilizing (SV) form where sufficient aldosterone is produced to avoid salt wasting. Both are accompanied by adrenocorticotropic hormone (ACTH)-driven increase in adrenal androgens with a virilizing effect on girls. Untreated, premature puberty with accelerated bone age will ensue. The prevalence of $21 \mathrm{OHD}$ shows large ethnic and geographic differences; the worldwide incidence is approximately 1/15,000 based on newborn screening (3).

The aim of the medical treatment is to provide sufficient glucocorticoid and mineralocorticoid replacement to suppress ACTH and adrenal androgen production without inducing glucocorticoid side effects (4). Monitoring of replacement therapy is difficult and lacks standardization in adults. Clinical assessment is not sensitive enough to identify subtle over- and under-treatment. Assay of the intermediates 17-hydroxyprogesterone (17OHP) and androstenedione is often used, but results are often difficult to interpret as cross-reactivity between steroids makes results unreliable (5). It is recommended to aim for a 17OHP concentration just above the upper reference level to avoid overtreatment with glucocorticoids (6) and in the recently published updated Endocrine Society Clinical Practice Guidelines (CAH due to steroid 21-hydroxylase deficiency) consistently timed hormone measurements relative to medication schedule and time of day is recommended (1). Drug fasting morning values of androstenedione and testosterone should be in the normal range for the patient's age and sex. However, current immunoassays for testosterone are prone to interferences in the female reference range (low levels of testosterone) and can be inaccurate $(7,8,9)$.

Liquid chromatography-tandem mass spectrometry (LC-MS/MS) has emerged as the method of choice for determination of steroid hormones. Advantages include its superior specificity compared to immunoassays, the possibility for multiplexing and low sample volume (10). This enables simultaneous analyses of other steroids that might aid diagnosis and monitoring. One such candidate is 21-deoxycortisol (21DF), which is elevated in patients with $21 \mathrm{OHD}$ (11) and a better marker than 17OHP for diagnosing infants $(12,13)$. The formation of cortisol via $21 \mathrm{DF}$ is an alternative pathway which is activated in patients with 21OHD (Fig. 1), but is lacking in healthy individuals (11).

Here, we compare immunoassays with LC-MS/MS in $210 H D$ patients in order to establish more precise biochemical monitoring in $\mathrm{CAH}$, and, for the first time, LC-MS/MS steroid hormone concentrations among different genotypes and phenotypes. In addition, we studied hormone panels and looked for individual variations and examined if other steroid precursors such as $21 \mathrm{DF}$ could provide better information for monitoring patients with $21 \mathrm{OHD}$.

\section{Subjects and methods}

\section{Study population}

Serum was obtained from 55 adult patients with $210 H D$ (17 men, 38 women; mean age 40.3 years (range 19-72) recruited from a previous study (14). Written informed consent was obtained. The patients were categorized as SW or SV phenotype, as defined by medical history and laboratory assessment (14). The diagnosis was verified by genotyping of the CYP21A2. Blood samples were collected in the morning before breakfast and medication. The Regional Ethics Committee of Western Norway and the Data Inspectorate of Norway approved the study. The study was performed according to the Helsinki Declaration.

\section{Steroid hormone quantitation by immunoassay}

Androstenedione and testosterone were analyzed with the Immulite 2000 competitive chemiluminescent immunoassay (Siemens). The androstenedione assay had a upper limit of detection of $35 \mathrm{nmol} / \mathrm{L}$. Samples above this limit were not diluted. 17OHP was measured by a competitive radioimmunoassay (RIA) method (Siemens) with an upper limit of detection of $47 \mathrm{nmol} / \mathrm{L}$. Samples above this limit were diluted to provide an accurate concentration (15).

\section{Steroid hormone quantitation by LC-MS/MS}

Serum concentrations of testosterone, androstenedione 17OHP, 21DF, 11-deoxycortisol (11DF), deoxycortisosterone (DOC), corticosterone, cortisone and cortisol were determined by an inhouse LC-MS/MS method developed at the Hormone Laboratory in Oslo. In brief, steroid hormones were extracted from serum with ethyl acetate using supported liquid extraction. Separation of steroid hormones was done by reversedphase liquid chromatography using a high-strength silicapentafluorophenyl (HSS-PFP) column. Detection was performed by positive electrospray ionization tandem mass spectrometry (triple quadrupole) as outlined in the Supplementary Subjects and methods (see section on Supplementary data given at the end of this paper).

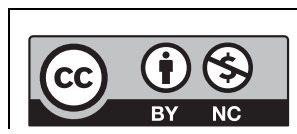

This work is licensed under a Creative Commons Attribution-NonCommercial 4.0 International License. 


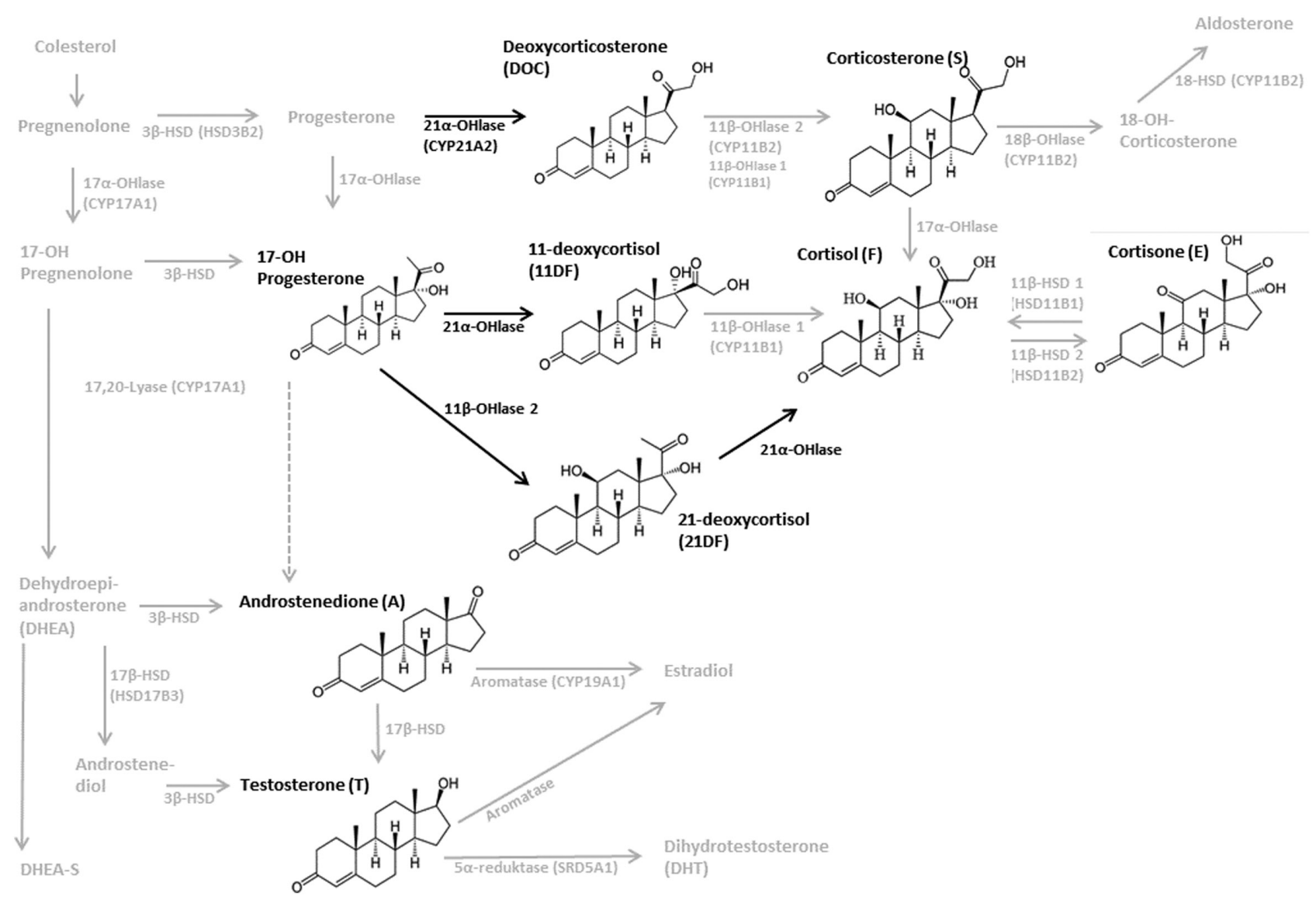

Figure 1

Steroid hormone synthesis. Analyzed steroids are marked with bold. The dashed line indicates formation of androstenedione from 17-hydroxyprogesterone.

LC-MS/MS reference values for adults (age $\geq 18$ ) are given in Table 1. The reference values were obtained from literature and their validity was confirmed with 20 routine samples (assumed healthy women, men and children) $(9,15,16$, $17,18)$. The reference value for $21 \mathrm{DF}$ was established inhouse by carefully evaluating individuals $(n=42)$ which had a detectable $21 \mathrm{DF}$ concentration $(>0.25 \mathrm{nmol} / \mathrm{L})$ obtained from routine samples. Our reference value of $>0.7 \mathrm{nmol} / \mathrm{L}$ is in agreement with a published reference value for $21 \mathrm{DF}$ (19).

\section{Genetic analysis and enzyme activity}

DNA was isolated from peripheral blood lymphocytes. Mutations in the CYP21A2 gene were identified by direct DNA sequencing and deletions were determined by realtime PCR (20). CYP21A2 mutations were divided into four groups according to their enzyme activity (in vitro): group Null (no enzyme activity), group A $(<2 \%)$, group B (2-10\%) and group C (10-75\%) $(21,22)$.

\section{Statistical analysis}

The results are given as mean ( \pm s.D.). For correlation and method comparison Passing-Bablok regression was performed with $\mathrm{Y}=\mathrm{LC}-\mathrm{MS} / \mathrm{MS}$ and $\mathrm{X}=\mathrm{immunoassay}$ (MedCalc Software 16.1). A difference in concentration between two methods $<10 \%$ is regarded as acceptable $(\mathrm{Y}=1 \pm 0.1 \mathrm{X})$. Pearson correlation coefficients $(r)$ were assessed for correlations between steroid hormones, and steroid hormones in different mutation groups were compared by one-way ANOVA if normally distributed and Kruskal-Wallis if not normally distributed. Statistical significance was defined as $P<0.05$.

\section{Results}

\section{Comparison of LC-MS/MS and immunoassay}

The concentrations of testosterone, androstenedione and 17OHP were generally lower when assayed with

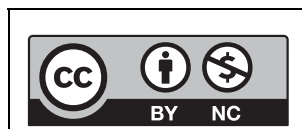

This work is licensed under a Creative Commons Attribution-NonCommercial 4.0 International License. 
Table 1 LC-MS/MS reference values for steroid hormones, current immunoassays values in parenthesis.

\begin{tabular}{|c|c|c|}
\hline Analyte & $\begin{array}{c}\text { Reference values, } \\
\text { adults } \geq \mathbf{1 8} \text { years }(\mathrm{nmol} / \mathrm{L})\end{array}$ & References \\
\hline Cortisol & $120-600$ & $\begin{array}{l}\text { Hormone Laboratory Haukeland University } \\
\text { Hospital Bergen (18) }\end{array}$ \\
\hline Cortisone & $13-92$ & Kulle et al. (9) \\
\hline Corticosterone & $1.3-36$ & Fanelli et al. (15) \\
\hline 11-Deoxycortisol & $\leq 3.2$ & Fanelli et al. (15) \\
\hline 21-Deoxycortisol & $\leq 0.7$ & Own data \\
\hline 17-Hydroxyprogesterone & & Mayo Medical Laboratories (17) \\
\hline Females, follicular phase & $\leq 2.4(1.2-9.9)$ & \\
\hline Females, luteal phase & $\leq 8.6(1.2-9.9)$ & \\
\hline Males & $\leq 6.7(1.8-7.8)$ & \\
\hline Deoxycortisol & $\leq 0.41$ & Costa-Barbosa et al. (11) \\
\hline Testosterone & $\leq 1.9(0.3-1.9)$ & Kushnir et al. (16) \\
\hline Females, postmenopausal & $\leq 1.1(0.2-1.1)$ & \\
\hline Males, age $18-40$ & $7.2-24(8.0-35)$ & \\
\hline Males, age $\geq 41$ & $4.6-24$ & \\
\hline Androstenedione & & Mayo Medical Laboratories (17) \\
\hline Females & $1.4-5.2(<11.5)$ & \\
\hline Males & $1.0-7.0(2.1-10.8)$ & \\
\hline
\end{tabular}

LC-MS/MS compared with immunoassay. Testosterone concentrations were 30\% lower in females (Fig. 2A), but only a small difference in concentration was observed in males (Fig. 2B). Androstenedione concentrations were 30\% lower (males and females combined) (Fig. 2E). Concentrations above $35 \mathrm{nmol} / \mathrm{L} \quad(n=12)$ obtained by immunoassay were excluded (above measuring range for immunoassay). Method comparison for 17OHP (males and females combined) revealed overall 23\% lower values when samples $>100 \mathrm{nmol} / \mathrm{L}$ (immunoassay) were excluded (Fig. 2D). When all samples were included, the difference was even greater (57\%) (Fig. 2C).

\section{1-Deoxycortisol (21DF)}

The correlation between $17 \mathrm{OHP}$ and 21DF was good when all samples were included $(r=0.87, P \leq 0.001)$ (Fig. 3A). When samples with a $17 \mathrm{OHP}$ concentration $>100 \mathrm{nmol} / \mathrm{L}$ were excluded, less correlation between 17OHP and 21DF was observed $(r=0.60, P \leq 0.001)$ (Fig. 3B). Three of the patients did not have measurable concentrations of 21DF. In these patients, the mutations were in group Null and A including del/I2 splice, I2 splice/I2 splice and del/del.

\section{Genotype, phenotype and steroid hormone profile}

Thirty-one individuals were classified in category Null and A, leading to the SW phenotype in 29 patients. Twenty-four individuals were classified in category B and C, of whom 22 had the SV phenotype. Thus, two individuals had a SV phenotype even though genetic

$\begin{array}{lr}\text { https://ec.bioscientifica.com } & \text { ○ } 2018 \text { The authors } \\ \text { https://doi.org/10.1530/EC-18-0453 } & \text { Published by Bioscientifica Ltd }\end{array}$

analysis indicated no enzyme activity and two individuals had a SW phenotype despite a genetic analysis indicating 2-10\% enzyme activity (group B).

Subjects in group Null had lower mean 11DF concentrations compared with subjects in group B; mean ( \pm s.D.) $0.153(0.20)$ vs $0.513 \pm(0.63) \mathrm{nmol} / \mathrm{L}(P=0.052)$. Concentrations of other steroid hormones did not differ significantly between the genotypes; however, large individual differences were observed (Fig. 4).

\section{Patient cases}

Four individuals had a phenotype which did not correspond to genetic analysis, and their individual hormone concentrations are given in Table 2. The steroids assayed by LC-MS/MS distal to the block fitted well with the phenotype.

One woman had a high testosterone concentration of $12.7 \mathrm{nmol} / \mathrm{L}$ assayed with immunoassay but $3.8 \mathrm{nmol} / \mathrm{L}$ with LC-MS/MS.

\section{Discussion}

It is well known that immunoassays and LC-MS/MS methods measure different concentrations of steroid hormones, primarily because immunoassays are more prone to cross-reactivity, especially in the low concentration range $(5,7)$. In our cohort of $210 \mathrm{HD}$ patients, acceptable correlations $(r>0.65)$ were achieved for 17OHP, androstenedione and testosterone (female and male range). As expected, the concentrations obtained

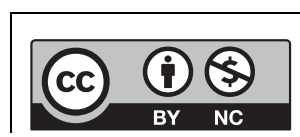

This work is licensed under a Creative Commons Attribution-NonCommercial 4.0 International License. 
A

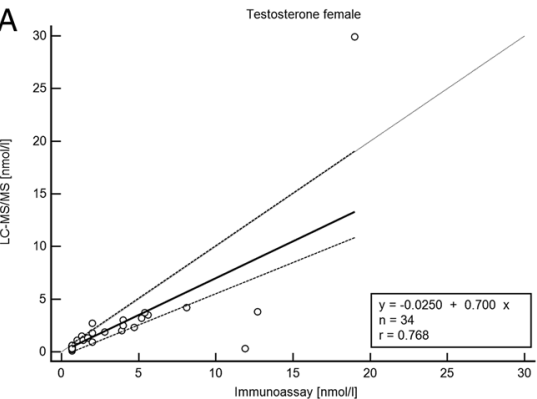

C

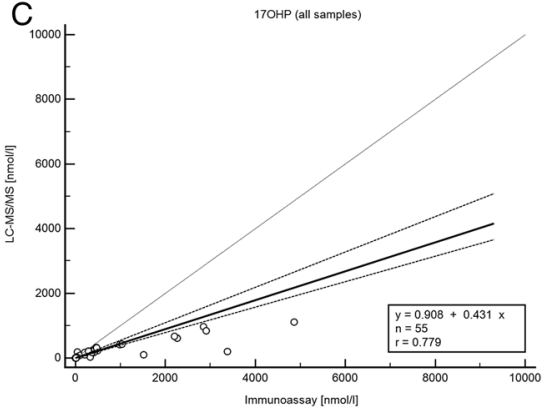

$E$

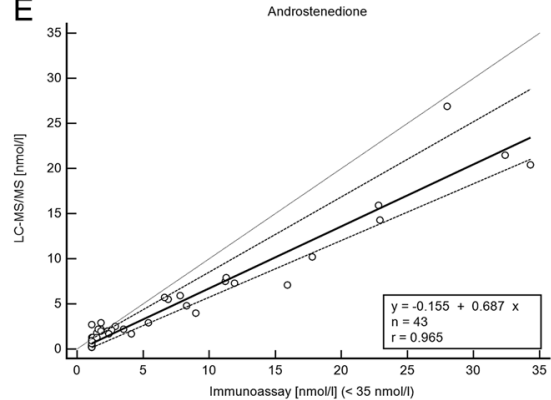

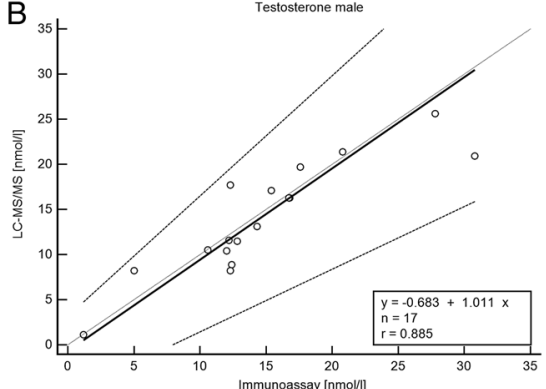

D

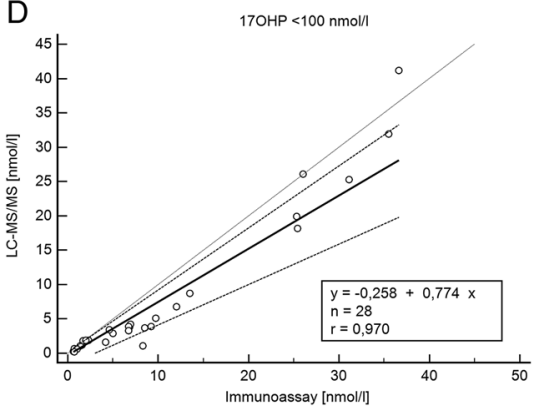

Figure 2

Comparison of LC-MS/MS (Y) and immunoassay (X) methods. Statistical analyses were carried out using the Passing-Bablok regression. The dashed lines indicate the $95 \%$ confidence interval for the regression line. (A) testosterone females; $(B)$ testosterone males; (C) $170 \mathrm{HP}$ all samples included; (D) 170HP samples $<100 \mathrm{nmol} / \mathrm{l}$ included; (E) androstenedione. with LC-MS/MS were lower compared to concentrations obtained with immunoassay. A difference in concentration of $10 \%$ between two methods obtained from PassingBablok regression is generally regarded as acceptable, that is, methods giving comparable concentrations (internal laboratory procedure). Large differences imply that the methods measure different concentrations and thus different reference values must be employed.

Immunoassays overestimate especially $17 \mathrm{OHP}$ and androstenedione concentrations in patients with $210 H D$ because of a general lack of specificity and a high degree of interference in these methods. This may in turn lead to overtreatment with glucocorticoids. In our study, testosterone was highly overestimated in one woman, where LC-MS/MS measured a testosterone concentration of $3.8 \mathrm{nmol} / \mathrm{L}$ and immunoassay $12.7 \mathrm{nmol} / \mathrm{L}$. A testosterone level of $12.7 \mathrm{nmol} / \mathrm{L}$ would normally result in intensification of the treatment and more likely overtreatment with glucocorticoids. We also performed a chromosome analysis due to this high value which showed a normal 46 XX karyotype.

Thus, LC-MS/MS methods are superior to immunoassays in this regard.

Many of the study patients had high levels of 17OHP in the morning which could indicate that they were not treated appropriately. However, higher doses of glucocorticoids may give more side effects such as obesity and osteoporosis. Biochemical monitoring of therapy in $\mathrm{CAH}$ is controversial and difficult as the serum hormones fluctuate with time of day and intake of glucocorticoid tablets. Hence, target concentrations are not clearly defined. A random test of serum hormones has limited value, but the therapeutic goal has until now been assessed by measurement of $17 \mathrm{OHP}$ in the mornings before intake of glucocorticoid tablets (6). A way to overcome this could be diurnal 17OHP curve analyzed from dried blood spots done at the patient's home (23). It is, however, only available in certain countries. https://ec.bioscientifica.com

https://doi.org/10.1530/EC-18-0453
(C) 2018 The authors Published by Bioscientifica Ltd
This work is licensed under a Creative Commons Attribution-NonCommercial 4.0 International License. 
A
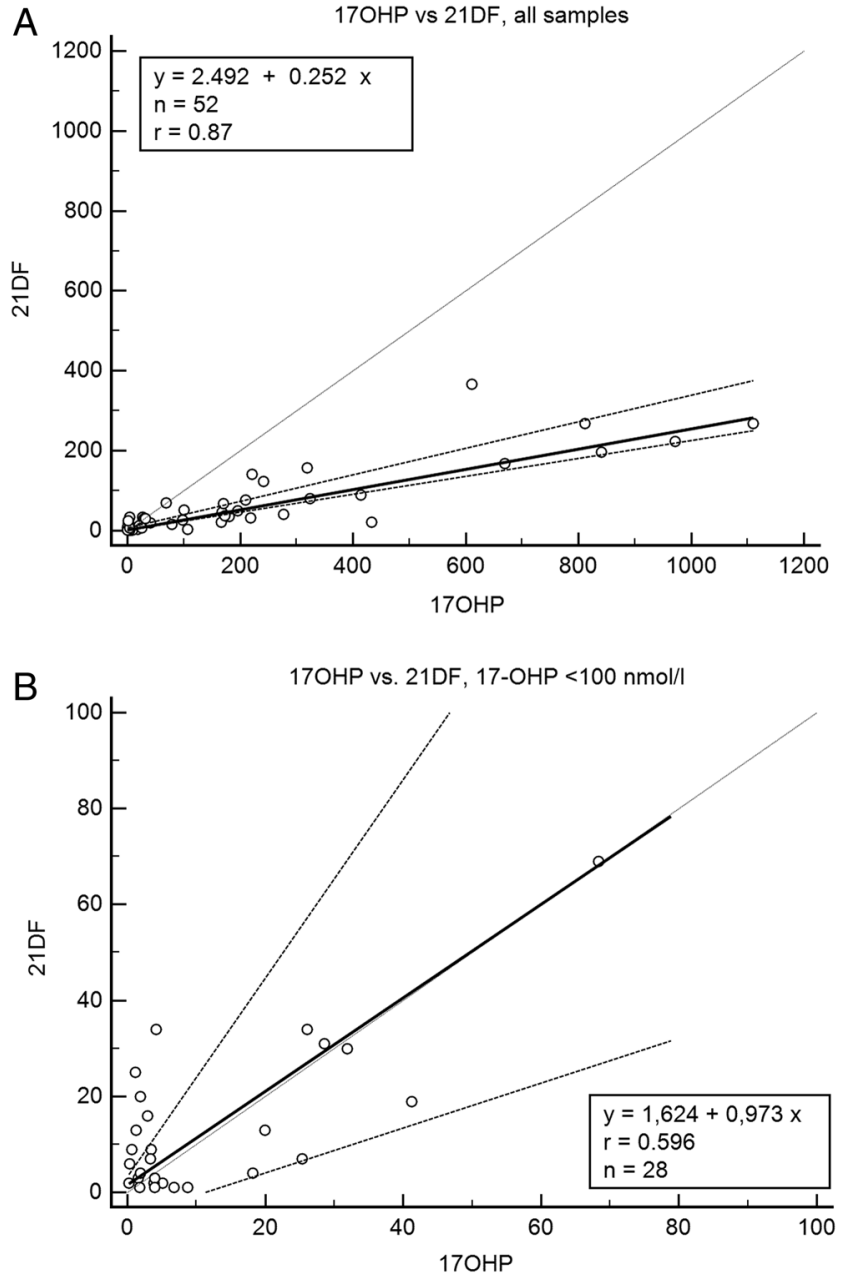

Figure 3

Passing-Bablok regression of 21-deoxycortisol (21DF) (Y) and 17-hydroxyprogesterone (17OHP) (X) with LC-MS/MS. The dashed lines indicate the $95 \%$ confidence interval for the regression line. (A) all samples included; (B) samples with $170 \mathrm{HP}<100 \mathrm{nmol} / \mathrm{l}$ included.

When methods for determinations for steroid hormones are changed from immunoassay to LC-MS/ MS, it is thus important that not only reference values are changed. Cut-off values for diagnosis and target levels for treatment must also be defined.

Previous studies have found that the measurement of 21DF may be helpful in the diagnosis of CAH (13). We did not find evidence for that 21DF is better than $17 \mathrm{OH}$ in monitoring patients with $\mathrm{CAH}$. In the screening for newborn errors of metabolism, 21DF may be a better discriminator for $\mathrm{CAH}$ compared to 17OHP. Especially in premature infants, $17 \mathrm{OHP}$ is often elevated in the first few days (12). The correlation between 17OHP and 21DF concentrations was good in our treated patients with $\mathrm{CAH}$. A positive $21 \mathrm{DF}$ concentration $(>0.7 \mathrm{nmol} / \mathrm{L})$ strongly indicates that the 21-hydroxylase activity is impaired. However, it is not clear whether overtreatment with glucocorticoids cause a decline in 21DF. If 21DF could be a better marker compared to 17OHP needs further evaluation. Compared to 17OHP, 21DF may be better for diagnosing adults with non-classic $\mathrm{CAH}$ due to 21OHD $(24,25)$. Whether 21DF is better than 17OHP to differentiate other disorders with elevated $17 \mathrm{OHP}$, such as PCOS needs to be evaluated $(26,27)$

There was no apparent association between patients who had negative 21DF and their medication (fludrocortisone dose and hydrocortisone equivalents). All three subjects with negative 21DF were females with a SW phenotype treated with prednisolone. Genetic analysis showed mutations consistent with group Null in one subject, while the other two were in group A. In these patients, the mutations were del/I2 splice, I2 splice/I2 splice and del/del, but other patients had these mutations and measurable 21DF concentrations. 21DF is most likely not superior to $17 \mathrm{OHP}$ in monitoring patients treated for 21OHD.

Patients who have a SW genotype, but present a SV phenotype have higher concentrations of the hormones after the $21 \mathrm{OH}$ enzymatic block (11DF, DOC, corticosterone, cortisol, cortisone) compared to patients who have a SV genotype but SW phenotype. LC-MS/MS analyses of these hormones fit well with the phenotype and provide valuable information. The patient examples in Table 2 show that the analysis of only a few steroid hormones may be misleading in the follow-up of $\mathrm{CAH}$ patients.

Another advantage of LC-MS/MS is that several hormones and glucocorticoid medication can be measured in one sample/run and an adrenal steroid profile can be established. By multiplexing, valuable information is gained. Furthermore, the updated Clinical Practice Guidelines (CAH due to steroid 21-hydroxylase deficiency) from November 2018 state that LC-MS/MS is the gold standard for blood and saliva measurements of steroids (1).

In our study of treated CAH patients, there seems to be a discrepancy between mutations detected and adrenal steroid hormone profile. This discrepancy is reduced when using LC-MS/MS which provides the ability to simultaneously analyze steroid hormones after the $21 \mathrm{OH}$ enzymatic block. Also, there is a lack of similarity in steroid hormone profile and clinical phenotype (SW vs SV). In compound heterozygous cases, the mildest mutation defines the genotype group. The correlation https://ec.bioscientifica.com https://doi.org/10.1530/EC-18-0453
C) 2018 The authors Published by Bioscientifica Ltd
This work is licensed under a Creative Commons Attribution-NonCommercial 4.0 International License. 

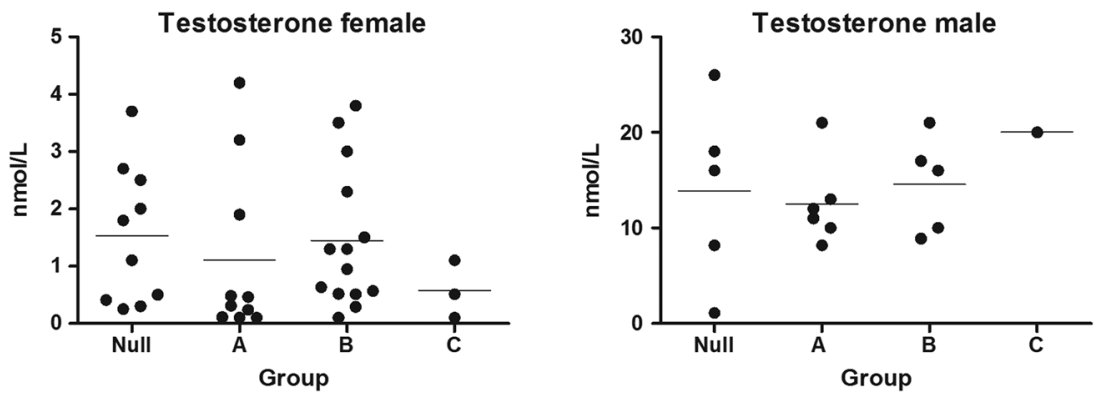

17-OH progesterone

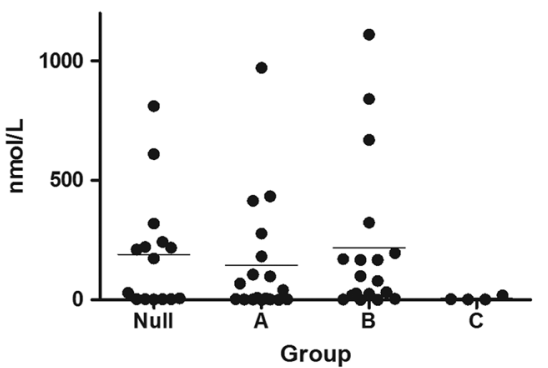

Androstenedione

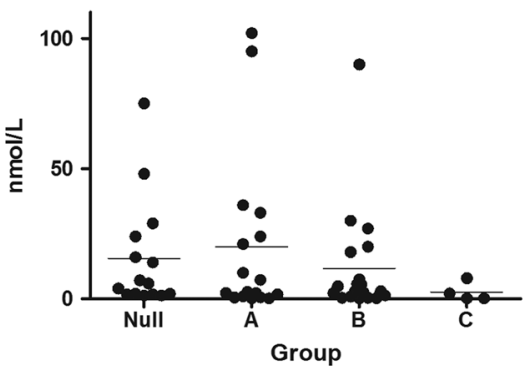

Corticosterone

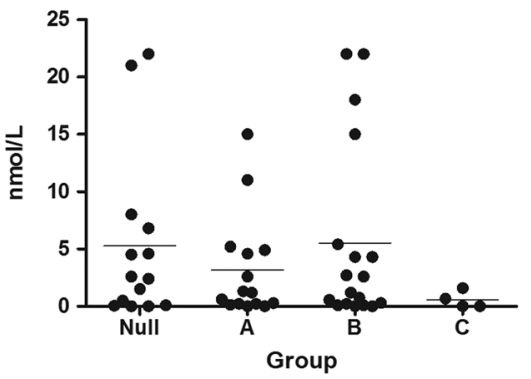

11-deoxycortisol
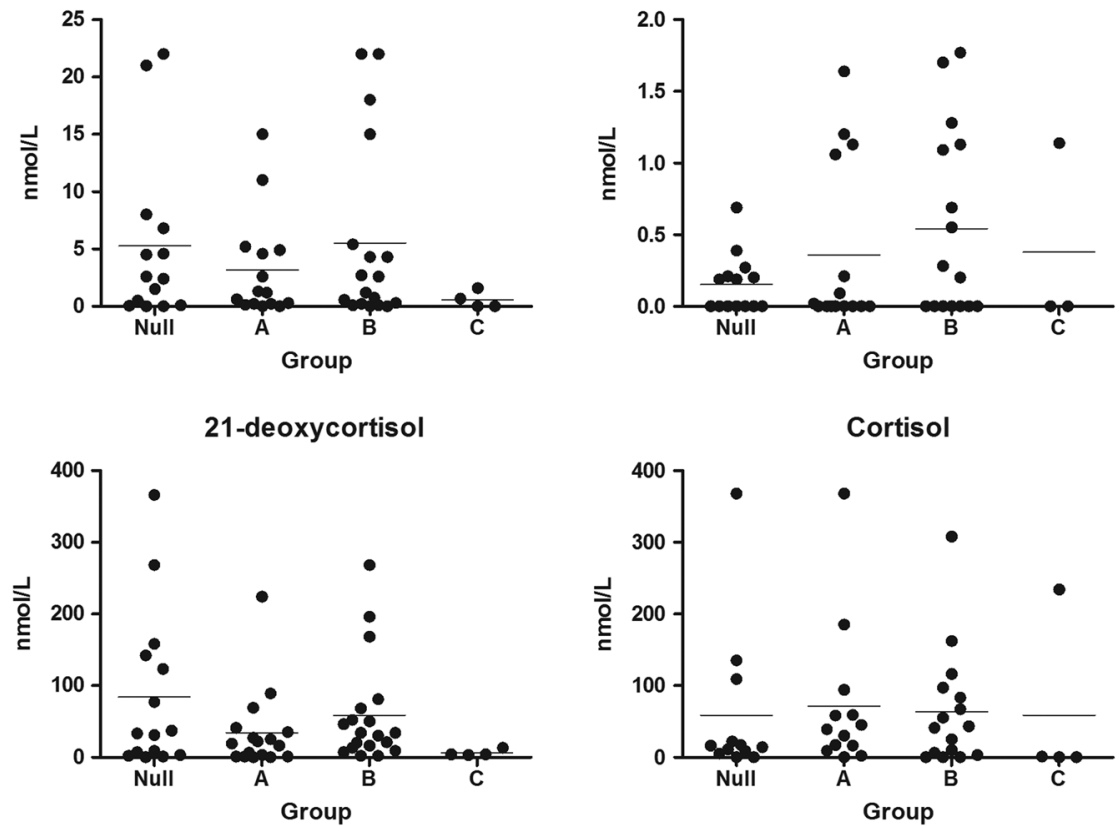

Figure 4

LC-MS/MS hormone profile ( $\mathrm{nmol} / \mathrm{L})$ in different mutation groups group; Null (complete enzyme impairment), group A (almost complete enzyme impairment $(<2 \%)$, group B (severe enzyme impairment, 2-10\%) and group C (partial impairment, $10-75 \%)$. Mean values are marked.

between genotype and clinical phenotype in 21OHD is usually high, however, not $100 \%$ (22), which may be due to artifacts when using PCR-based genotyping (28, 29, 30). A source of phenotype-genotype variability is the leakiness of splice mutations (31). Thus, treatment should be given according to the clinical picture.

In conclusion, LC-MS/MS methods are superior to immunoassays in monitoring patients with 21OHD on corticosteroid replacement therapy as they are more specific and can be multiplexed. Immunoassays seem

https://ec.bioscientifica.com

https://doi.org/10.1530/EC-18-0453

(c) 2018 The authors Published by Bioscientifica Ltd to overestimate high concentrations of $17 \mathrm{OHP}$ and androstenedione considerably. With the possibility of obtaining steroid hormone profiles, LC-MS/MS methods provide a more complete picture of the whole hormone cascade compared to immunoassay methods. Some of the examples show that the analysis of only a few steroid hormones may be misleading in the follow-up of $\mathrm{CAH}$ patients. $21 \mathrm{DF}$ is most likely not superior to $17 \mathrm{OHP}$ in monitoring patients treated for 21OHD, but further investigation is needed. 


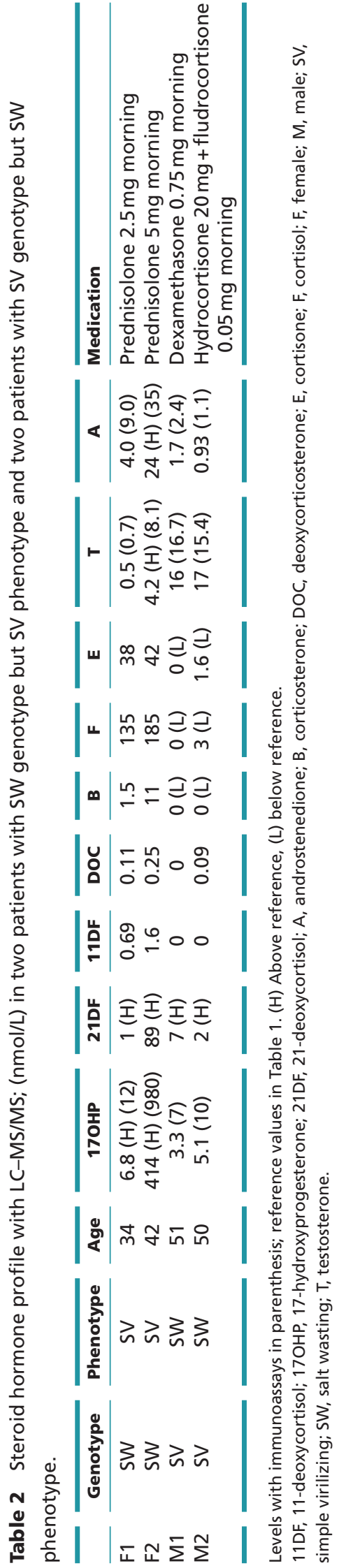

https://ec.bioscientifica.com https://doi.org/10.1530/EC-18-0453
(C) 2018 The authors Published by Bioscientifica Ltd
Supplementary data

This is linked to the online version of the paper at https://doi.org/ EC-18-0453.

\section{Declaration of interest}

The authors declare that there is no conflict of interest that could be perceived as prejudicing the impartiality of the research reported.

\section{Funding}

This work did not receive any specific grant from any funding agency in the public, commercial, or not-for-profit sector.

\section{Acknowledgements}

The authors thank Liv Hanne Bakke at the Hormone Laboratory in Oslo for the analytical work on LC-MS/MS and the Hormone Laboratory in Bergen for the analytical work on immunoassay.

\section{References}

1 Speiser PW, Arlt W, Auchus RJ, Baskin LS, Conway GS, Merke DP, Meyer-Bahlburg HFL, Miller WL, Murad MH, Oberfield SE, et al. Congenital adrenal hyperplasia due to steroid 21-hydroxylase deficiency: an Endocrine Society clinical practice guideline. Journal of Clinical Endocrinology and Metabolism 2018103 1-46. (https://doi. org/10.1210/jc.2017-02141)

2 Falhammar H \& Thorén M. Clinical outcomes in the management of congenital adrenal hyperplasia. Endocrine 201241 355-373. (https:// doi.org/10.1007/s12020-011-9591-x)

3 Pang S. Newborn screening for congenital adrenal hyperplasia. Pediatric Annals 200332 516-523. (https://doi.org/10.3928/00904481-20030801-09)

4 Bachelot A, Grouthier V, Courtillot C, Dulon J \& Touraine P. Management of endocrine disease: Congenital adrenal hyperplasia due to 21-hydroxylase deficiency: update on the management of adult patients and prenatal treatment. European Journal of Endocrinology 2017176 R167-R181. (https://doi.org/10.1530/ EJE-16-0888)

5 Methlie P, Hustad SS, Kellmann R, Almas B, Erichsen MM, Husebye E \& Løvås K. Multisteroid LC-MS/MS assay for glucocorticoids and androgens, and its application in Addison's disease. Endocrine Connections 20132 125-136. (https://doi.org/10.1530/EC-13-0023)

6 El-Maouche D, Arlt W and Merke DP. Congenital adrenal hyperplasia. Lancet 2017390 2194-2210. (https://doi.org/10.1016/ S0140-6736(17)31431-9)

7 Taieb J, Mathian B, Millot F, Patricot MC, Mathieu E, Queyrel N, Lacroix I, Somma-Delpero C \& Boudou P. Testosterone measured by 10 immunoassays and by isotope-dilution gas chromatography-mass spectrometry in sera from 116 men, women, and children. Clinical Chemistry 200349 1381-1395. (https://doi.org/10.1373/49.8.1381)

8 Herold DA \& Fitzgerald RL. Immunoassays for testosterone in women: better than a guess? Clinical Chemistry 200349 1250-1251. (https://doi.org/10.1373/49.8.1250)

9 Kulle AE, Welzel M, Holterhus PM \& Riepe FG. Implementation of a liquid chromatography tandem mass spectrometry assay for eight adrenal C-21 steroids and pediatric reference data. Hormone Research in Paediatrics 201379 22-31. (https://doi. org/10.1159/000346406)

10 Van den Ouweland JM \& Kema IP. The role of liquid chromatography-tandem mass spectrometry in the clinical laboratory. Journal of Chromatography B: Analytical Technologies in

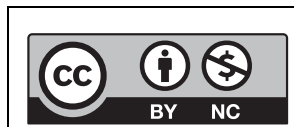

This work is licensed under a Creative Commons Attribution-NonCommercial 4.0 International License. 
the Biomedical and Life Sciences 2012 883-884 18-32. (https://doi. org/10.1016/j.jchromb.2011.11.044)

11 Costa-Barbosa FA, Tonetto-Fernandes VF, Carvalho VM, Nakamura OH, Moura V, Bachega TA, Vieira JG \& Kater CE. Superior discriminating value of ACTH-stimulated serum 21-deoxycortisol in identifying heterozygote carriers for 21-hydroxylase deficiency. Clinical Endocrinology 201073 700-706. (https://doi.org/10.1111/ j.1365-2265.2010.03871.x)

12 Janzen N, Peter M, Sander S, Steuerwald U, Terhardt M, Holtkamp U \& Sander J. Newborn screening for congenital adrenal hyperplasia: additional steroid profile using liquid chromatography-tandem mass spectrometry. Journal of Clinical Endocrinology and Metabolism 200792 2581-2589. (https://doi.org/10.1210/jc.2006-2890)

13 Fiet J, Le Bouc Y, Guechot J, Helin N, Maubert MA, Farabos D \& Lamaziere A. A liquid chromatography/tandem mass spectometry profile of 16 serum steroids, including 21-deoxycortisol and 21-deoxycorticosterone, for management of congenital adrenal hyperplasia. Journal of the Endocrine Society 20171 186-201. (https:// doi.org/10.1210/js.2016-1048)

14 Nermoen I, Husebye ES, Svartberg J \& Løvås K. Subjective health status in men and women with congenital adrenal hyperplasia: a population-based survey in Norway. European Journal of Endocrinology 2010163 453-459. (https://doi.org/10.1530/EJE-10-0284)

15 Fanelli F, Belluomo I, Di Lallo VD, Cuomo G, De Iasio R, Baccini M, Casadio E, Casetta B, Vicennati V, Gambineri A, et al. Serum steroid profiling by isotopic dilution-liquid chromatography-mass spectrometry: comparison with current immunoassays and reference intervals in healthy adults. Steroids 201176 244-253. (https://doi. org/10.1016/j.steroids.2010.11.005)

16 Kushnir MM, Blamires T, Rockwood AL, Roberts WL, Yue B, Erdogan E, Bunker AM \& Meikle AW. Liquid chromatographytandem mass spectrometry assay for androstenedione, dehydroepiandrosterone, and testosterone with pediatric and adult reference intervals. Clinical Chemistry 201056 1138-1147. (https:// doi.org/10.1373/clinchem.2010.143222)

17 Mayo Clinic Laboratories. Mayo reference values. Rochester, MN, USA: Mayo Foundation for Medical Education and Research, 2016. (available at: https://www.mayocliniclabs.com/test-catalog/Clinical+ and+Interpretive/9231).

18 Helse Bergen. Haukeland, refereanseområde LCMS. Bergen, Norway: Helse Bergen HF Haukeland universitetssjukehus, 2016. (available at: http://www.analyseoversikten.no/analyse/26).

19 Costa-Barbosa FA, Carvalho VM, Nakamura OH, Bachega TA, Vieira JG \& Kater CE. Zona fasciculata 21-hydroxysteroids and precursor-to-product ratios in 21-hydroxylase deficiency: further characterization of classic and non-classic patients and heterozygote carriers. Journal of Endocrinological Investigation 2011 34 587-592.

20 Nermoen I, Brønstad I, Fougner KJ, Svartberg J, Øksnes M, Husebye ES \& Løvås K. Genetic, anthropometric and metabolic features of adult Norwegian patients with 21-hydroxylase deficiency. European Journal of Endocrinology 2012167 507-516. (https://doi. org/10.1530/EJE-12-0196)
21 Wedell A, Thilen A, Ritzen EM, Stengler B \& Luthman H. Mutational spectrum of the steroid 21-hydroxylase gene in Sweden: implications for genetic diagnosis and association with disease manifestation. Journal of Clinical Endocrinology and Metabolism 199478 1145-1152. (https://doi.org/10.1210/jcem.78.5.8175971)

22 Hannah-Shmouni F, Chen W \& Merke DP. Genetics of congenital adrenal hyperplasia. Endocrinology and Metabolism Clinics of North America 201746 435-458. (https://doi.org/10.1016/j.ecl.2017.01.008)

23 Falhammar H, Filipsson Nyström H, Wedell A, Brismar K \& Thorén M. Bone mineral density, bone markers, and fractures in adult males with congenital adrenal hyperplasia. European Journal of Endocrinology 2013168 331-341. (https://doi.org/10.1530/ EJE-12-0865)

24 Gourmelen M, Gueux B, Pham Huu Trung MT, Fiet J, RauxDemay MC \& Girard F. Detection of heterozygous carriers for 21-hydroxylase deficiency by plasma 21-deoxycortisol measurement. Acta Endocrinologica 1987116 507-512. (https://doi.org/10.1530/ acta.0.1160507)

25 Fiet J, Gueux B, Gourmelen M, Kuttenn F, Vexiau P, Couillin P, Pham-Huu-Trung MT, Villette JM, Raux-Demay MC, Galons H, et al. Comparison of basal and adrenocorticotropin-stimulated plasma 21-deoxycortisol and 17-hydroxyprogesterone values as biological markers of late-onset adrenal hyperplasia. Journal of Clinical Endocrinology and Metabolism 198866 659-667. (https://doi. org/10.1210/jcem-66-4-659)

26 Reinehr T, Kulle A, Rothermel J, Knop-Schmenn C, Lass N, Bosse C $\&$ Holterhus PM. Longitudinal analyses of the steroid metabolome in obese PCOS girls with weight loss. Endocrine Connections 20176 213-224. (https://doi.org/10.1530/EC-17-0051)

27 Keefe CC, Goldman MM, Zhang K, Clarke N, Reitz RE \& Welt CK. Simultaneous measurement of thirteen steroid hormones in women with polycystic ovary syndrome and control women using liquid chromatography-tandem mass spectrometry. PLOS ONE 20149 e93805. (https://doi.org/10.1371/journal.pone.0093805)

28 Day DJ, Speiser PW, Schulze E, Bettendorf M, Fitness J, Barany F \& White PC. Identification of non-amplifying CYP21 genes when using PCR-based diagnosis of 21-hydroxylase deficiency in congenital adrenal hyperplasia (CAH) affected pedigrees. Human Molecular Genetics 19965 2039-2048. (https://doi.org/10.1093/hmg/5.12.2039)

29 Schulze E, Bettendorf M, Maser-Gluth C, Decker M \& Schwabe U. Allele-dropout using PCR-based diagnosis for the splicing mutation in intron-2 of the CYP21B-gene: successful amplification with a Taq/Pwo-polymerase mixture. Endocrine Research 199824 637-641. (https://doi.org/10.3109/07435809809032662)

30 Van de Velde H, Sermon K, De Vos A, Lissens W, Joris H, Vandervorst M, Van Steirteghem A \& Liebaers I. Fluorescent PCR and automated fragment analysis in preimplantation genetic diagnosis for 21-hydroxylase deficiency in congenital adrenal hyperplasia. Molecular Human Reproduction 19995 691-696. (https://doi. org/10.1093/molehr/5.7.691)

31 Speiser PW \& White PC. Congenital adrenal hyperplasia. New England Journal of Medicine 2003349 776-788. (https://doi. org/10.1056/NEJMra021561)

Received in final form $\mathbf{5}$ November 2018

Accepted 7 December 2018

Accepted Preprint published online 7 December 2018 https://ec.bioscientifica.com

https://doi.org/10.1530/EC-18-0453 (c) 2018 The authors

Published by Bioscientifica Ltd

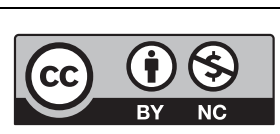

This work is licensed under a Creative Commons Attribution-NonCommercial 4.0 International License. 